\title{
Left heart ventricle function in children snoring due to adeno-tonsillar hypertrophy
}

\author{
Julia Mirecka' , Anna Mazurek-Kula², Katarzyna Ostrowska², Jarosław Andrzejewski ${ }^{3}$, \\ Wiesław Konopka ${ }^{4}$, Małgorzata Stańczyk ${ }^{1}$, Marcin Tkaczyk ${ }^{1}$ \\ 'Department of Paediatrics, Immunology, and Nephrology, Polish Mother's Memorial Hospital Research Institute, \\ Lodz, Poland \\ 2Department of Cardiology, Polish Mother's Memorial Hospital Research Institute, Lodz, Poland \\ ${ }^{3}$ Department of Children's Otolaryngology, Audiology, and Phoniatrics, Central Clinical Hospital, Lodz, Poland \\ ${ }^{4}$ Department of Otolaryngology, Polish Mother's Memorial Hospital Research Institute, Lodz, Poland
}

\section{ABSTRACT}

Introduction: Nasopharyngeal lymphatic tissue hypertrophy is the most common cause of sleep breathing disorders in children. Obstructive sleep apnoea has a proven adverse effect on the control of hypertension and the condition of left ventricle in adults. It is not clear whether snoring can have a negative effect on the selected echocardiographic parameters of the left ventricle.

Aim of the study: The aim of the study was to evaluate the selected parameters of the left ventricular structure and function in snoring children who had undergone adenoidectomy, adenotonsillectomy, or tonsillectomy in order to restore patency of the upper respiratory tract.

Material and methods: The study group consisted of 50 snoring children with nasopharyngeal lymphatic tissue hypertrophy. The control group contained 20 children without sleep breathing disorders. The age of children was between five and 14 years. Functional and structural echocardiographic parameters were assessed before and at three and six months after ENT surgery.

Results: The echocardiographic evaluation showed that the values of selected parameters describing the left ventricular anatomy and systolic-diastolic function were normal and did not differ significantly between the study group and the control group at any stage of the study.

Conclusions: Snoring reported by parents does not affect adversely left ventricle structure or function in children. Unlike in adults, myocardial overload is not common in snoring children.

\section{KEY WORDS:}

child, echocardiography, left heart ventricle, adenoidectomy, tonsillectomy, snoring.

\section{INTRODUCTION}

Palatine and adenoid tonsillar hypertrophy is very common in the paediatric population. It is estimated that this problem affects approximately $10 \%$ of school-age children [1]. The management of tonsillar hypertrophy depends on symptoms and accompanying complications. Sleep-disordered breathing (SDB) is one of the most important indications for tonsil removal, both in adenoid and palatine tonsillar hypertrophy. Primary snoring (PS)

\section{ADDRESS FOR CORRESPONDENCE:}

Julia Mirecka, Department of Paediatrics, Immunology and Nephrology, Polish Mother's Memorial Hospital Research Institute, 281/289 Rzgowska St., 93-338 Lodz, Poland, ORCID: 0000-0002-3460-4895,

e-mail: julia.mirecka@gmail.com 
is the mildest form of the disease, with the ailments occurring at least three times per week. Breathing disorders during sleep in adults are proven to be associated with an increased risk of cardiovascular diseases [2]. This relationship is particularly visible in the most severe form of SDB, i.e. obstructive sleep apnoea (OSA) $[3,4]$. There are divergent reports in the literature on the impact of tonsillar hypertrophy and snoring on the cardiovascular system in children. Research has already shown that SDB can adversely affect right heart ventricle function and pulmonary circulation $[5,6]$. Hypertension has a well-established negative impact on left ventricle structure and function [7]. Severely snoring adults commonly have higher blood pressure compared to non-snorers and present left myocardial overload [8]. Therefore, the aim of the study was to evaluate the selected structural and functional left ventricular parameters in children with SDB and nasopharyngeal lymphatic tissue hypertrophy before and after restoring patency of upper respiratory tract.

\section{MATERIAL AND METHODS}

The study was a prospective observation of changes in the selected parameters of left heart ventricle assessed in the echocardiography before and after restoring patency of the nasopharynx through adenoidectomy, adenotonsillectomy or tonsillectomy. The study involved 70 children: 50 in the study group ( 34 boys and 16 girls) and 20 in the control group (seven boys and 14 girls). The children from both groups did not differ in terms of standardised indices of height, weight, and body mass index (Table 1).

The study group consisted of children with nasopharyngeal lymphatic tissue hypertrophy, who were qualified for adenoidectomy and/or tonsillectomy by a paediatric otolaryngologist, based on clinical criteria. The basic

TABLE 1. Group characteristics

\begin{tabular}{|l|c|c|c|}
\hline $\begin{array}{l}\text { Beginning } \\
\text { of the study }\end{array}$ & $\begin{array}{c}\text { Study group } \\
(n=50)\end{array}$ & $\begin{array}{c}\text { Control group } \\
(n=20)\end{array}$ & $p$ \\
\hline Sex: boys & $34(68 \%)$ & $7(35 \%)$ & 0.0236 \\
\hline Age & $7.00(6.00-8.00)$ & $8.00(7.00-10.50)$ & 0.1059 \\
\hline $\begin{array}{l}\text { z-score } \\
\text { BMI }\end{array}$ & $0.37(-0.68-1.57)$ & $-0.16(-0.47-0.44)$ & 0.2687 \\
\hline $\begin{array}{l}\text { z-score } \\
\text { height }\end{array}$ & $-0.08(-0.06-0.17)$ & $0.26(-0.30-1.05)$ & 0.1668 \\
\hline $\begin{array}{l}z \text {-score body } \\
\text { weight }\end{array}$ & $0.04(-0.44-1.44)$ & $-0.17(-0.46-0.85)$ & 0.6286 \\
\hline SBP z-score & $0.043(-1.03-0.43)$ & $-0.35(-1.14-0.21)$ & 0.7551 \\
\hline DBP z-score & $-0.07(-0.48-0.99)$ & $-0.51(-1.2-0.2)$ & 0.2232 \\
\hline
\end{tabular}

Data shown as the median and interquartile ranges. BMI - body mass index, SBP - systolic blood pressure, DBP - diastolic blood pressure criterion for inclusion in the study was the presence of breathing disorders during sleep manifested by snoring (at least three times per week) for at least six months. The evaluation of the degree of breathing disorders was based on the medical history taken from parents. It allowed diagnosis of persistent breathing disorders during sleep caused by tonsillar hypertrophy. The following clinical symptoms and effects of tonsillar hypertrophy were evaluated: difficulty breathing during sleep associated with snoring, breaks in breathing observed by children, frequent awakenings, excessive sweating, bedwetting, and persistent breathing through the mouth. In order to identify an improvement in SDB and the accompanying symptoms after surgery, parents were asked to complete a survey during subsequent stages of the study. The children from the study group were assessed three times - before surgery - ear, nose, and throat (ENT) procedure (at least a week before), after a period of respiratory disorders occurring during sleep and lasting for at least six months, and then three and six months after surgery.

The control group consisted of healthy children who were examined once. Exclusion criteria included: refusal to participate in the study, participation in another study, age below five years and above 18 years, unstable clinical condition, chronic kidney disease at stages 3-5, arterial hypertension secondary to another pathology, heart or circulatory system failure that could influence the evaluated parameters or prevent the correct performance of examinations, diabetes, taking drugs that could affect the assessed parameters or prevent the correct performance of examinations, congenital metabolism defects, e.g. hypercholesterolaemia, or acute inflammation.

An ultrasound examination of the heart was performed by two experienced paediatric cardiologists. The procedure was carried out using a Hitachi ALOCA Prosound a 6 device (Hitachi Aloca Medical Ltd., Japan) with a $5-\mathrm{MHz}$ sector head. The mass of the left ventricle was evaluated based on the thickness of the ventricular walls and the intraventricular dimension in diastole. The left ventricular mass index was assessed by relating the dimensions of the ventricle to the child's body surface (LVM/BSA Index). In the study group, the left ventricular mass index was considered normal when its value was $<95^{\text {th }}$ percentile for given sex and age. The left ventricular systolic function was evaluated by measuring the shortening fraction (SF), ejection fraction (EF), stroke volume (SV), and cardiac index (CI), which corresponds to the normalised value of cardiac output (CO) converted to the body surface area (CO/BSA). The evaluation of the diastolic function was performed on the basis of the Doppler examination of the mitral inflow - the ratio of peak velocity blood flow from gravity in early diastole to peak velocity flow in late diastole caused by atrial contraction (E/A) was determined. The study was approved by the Bioethics Committee. 


\section{RESULTS}

The study revealed that snoring children were normotensive. We found no differences between snorers and non-snorers at each stage of the study (Table 1).

After the surgery $z$-scores of systolic and diastolic blood pressures decreased significantly: 0.043 vs. -0.187 vs. $-0.761, p=0.0004$ and -0.07 vs. -0.22 vs. -0.41 , $p<0.0001$, respectively.

The values of the basic parameters describing the left ventricular anatomy and systolic-diastolic function were normal and did not differ significantly between the study group and the control group at any stage of the study. An increase in the left ventricular late diastolic dimension was observed six months after the procedure $(p=0.0294)$ with a transient elevation in cardiac output and cardiac index. No significant changes or differences were found in other parameters between the study and control group. No correlation between LVH parameters and blood pressure changes or clinical snoring score were found. The echocardiographic results are summarised in Table 2.

\section{DISCUSSION}

The study showed that children snoring due to tonsillar hypertrophy have normal left ventricular parameters assessed by echocardiography, which corresponds with their normal blood pressure. It has been concluded that the restoration of nasopharyngeal patency did not result in any significant changes in this respect. According to previous reports, SDB may have an impact primarily on the right ventricular parameters and pressure in the pulmonary circulation $[5,6]$; therefore, in this context of utmost importance in these children would be the evaluation of the right ventricular dimensions, grade and gradient of tricuspid and pulmonary valve regurgitation, and RV-MPI (Tei index for right ventricular). However, the features of left ventricular hypertrophy are also observed in the paediatric population burdened by OSA and this may be an element combining tonsillar hypertrophy with elevated blood pressure. Therefore, searching for the relationship between snoring and blood pressure, the study evaluated mainly the left ventricular parameters. Amin

TABLE 2. Basic parameters assessed in the echocardiographic examination in the study group and control group

\begin{tabular}{|c|c|c|c|c|c|c|c|c|}
\hline \multirow[t]{2}{*}{ Parameter } & \multicolumn{3}{|c|}{ Group B } & \multirow[t]{2}{*}{ Group K } & \multicolumn{4}{|c|}{$p$} \\
\hline & Visit 1 & Visit 2 & Visit 3 & & $\begin{array}{c}\text { Significance } \\
\text { of changes } \\
\text { in parameters } \\
\text { in the study group }\end{array}$ & \begin{tabular}{|c|} 
Visit 1 to \\
the control \\
group
\end{tabular} & \begin{tabular}{|c|} 
Visit 2 \\
to the control \\
group
\end{tabular} & $\begin{array}{l}\text { Visit } 3 \text { to } \\
\text { the control } \\
\text { group }\end{array}$ \\
\hline LVPWs, mm & $9(8-10)$ & $9(8-11)$ & $9(8-10)$ & $9(8-10)$ & 0.92 & 1.0 & 1.0 & 1.0 \\
\hline IVSs, $\mathrm{mm}$ & $9(8-10)$ & $9.5(8-11)$ & $9(8-11)$ & $9(9-11)$ & 0.0634 & 0.1032 & 1.0 & 1.0 \\
\hline LVIDs, mm & $\begin{array}{c}24 \\
(23-26)\end{array}$ & $\begin{array}{c}25 \\
(22-27)\end{array}$ & $\begin{array}{c}25 \\
(24-26)\end{array}$ & $\begin{array}{c}23 \\
(22-27)\end{array}$ & 0.1246 & 0.9222 & 0.9504 & 0.4755 \\
\hline LVIDd, mm & $\begin{array}{c}38 \\
(36-41)\end{array}$ & $\begin{array}{c}38 \\
(36-41)\end{array}$ & $\begin{array}{c}39 \\
(37-41)\end{array}$ & $\begin{array}{c}37 \\
(35-43)\end{array}$ & 0.0294 & 1.0 & 1.0 & 0.3429 \\
\hline IVSd, mm & $7(6-8)$ & $7(6-8)$ & $7(6-8)$ & $7(6-8)$ & 0.0956 & 1.0 & 1.0 & 1.0 \\
\hline LVPWd, mm & $6(5-7)$ & $7(6-8)$ & $7(6-7)$ & $6(6-7)$ & 0.5366 & 1.0 & 0.8820 & 1.0 \\
\hline LVMI, g/m² & $\begin{array}{c}65.5 \\
(57-79)\end{array}$ & $\begin{array}{c}72 \\
(62-83)\end{array}$ & $\begin{array}{c}68 \\
(62-85)\end{array}$ & $\begin{array}{c}62 \\
(53-75)\end{array}$ & 0.0505 & 0.7941 & 1.0 & 0.1374 \\
\hline $\mathrm{EF}, \%$ & $\begin{array}{c}65 \\
(62-70)\end{array}$ & $\begin{array}{c}67.4 \\
(62.2-71.4)\end{array}$ & $\begin{array}{c}66.2 \\
(62.6-9.8)\end{array}$ & $\begin{array}{c}67 \\
(62-72)\end{array}$ & 0.2764 & 0.6117 & 1.0 & 1.0 \\
\hline $\mathrm{FS}, \%$ & $\begin{array}{c}35 \\
(33-39)\end{array}$ & $\begin{array}{c}36.7 \\
(33-41)\end{array}$ & $\begin{array}{c}35.9 \\
(33.3-38.9)\end{array}$ & $\begin{array}{c}37 \\
(33-42)\end{array}$ & 0.6556 & 0.6720 & 1.0 & 1.0 \\
\hline$E / A$ & $\begin{array}{c}1.71 \\
(1.54-2.03)\end{array}$ & $\begin{array}{c}1.92 \\
(1.68-2.07)\end{array}$ & $\begin{array}{c}1.98 \\
(1.7-2.33)\end{array}$ & $\begin{array}{c}2.11 \\
(1.58-2.32)\end{array}$ & 0.9316 & 0.4494 & 0.8178 & 1.0 \\
\hline $\mathrm{CO}, \mathrm{l} / \mathrm{min}$ & $\begin{array}{c}3.38 \\
(2.7-4.46)\end{array}$ & $\begin{array}{c}3.83 \\
(3.33-4.76)\end{array}$ & $\begin{array}{c}3.55 \\
(3.04-3.93)\end{array}$ & $\begin{array}{c}3.69 \\
(2.86-4.42)\end{array}$ & 0.0438 & 1.0 & 1.0 & 1.0 \\
\hline $\mathrm{Cl}, \mathrm{l} / \mathrm{min} / \mathrm{m}^{2}$ & $\begin{array}{c}3.41 \\
(2.81-4.20)\end{array}$ & $\begin{array}{c}3.66 \\
(3.00-4.18)\end{array}$ & $\begin{array}{c}3.28 \\
(2.67-3.88)\end{array}$ & $\begin{array}{c}3.71 \\
(2.79-4.35)\end{array}$ & 0.0230 & 1.0 & 1.0 & 1.0 \\
\hline
\end{tabular}

The values are expressed as median and interquartile ranges (quartile 25 and 75). Group B - study group, Group K - control group, LVPWs - thickness of the left ventricular posterior wall in systole, IVSs - thickness of the interventricular septum in systole, LVIDs - left ventricular end-systolic dimension, LVIDd - left ventricular end-diastolic dimension, IVSd - thickness of the interventricular septum in diastole, LVPWd - thickness of the left ventricular posterior wall in diastole, LVMI - left ventricular mass index, EF - ejection fraction, FS - shortening fraction, E/A - ratio of peak velocity blood flow from gravity in early diastole (E) to peak velocity flow in late diastole caused by atrial contraction $(A), C O$ - cardiac output, $\mathrm{Cl}$ - cardiac index 
et al. compared the dimensions of the right and left ventricle, the left ventricular mass, and the geometry index in children with OSA and with primary snoring. The study demonstrated that the left ventricular mass index and the relative wall thickness were higher in the OSA group than in the PS group $(p=0.012$ and $p<0.0001$, respectively) [9]. Villa et al. demonstrated that, despite normal blood pressure, children with OSA may suffer from left ventricular dysfunction. Using a two-dimensional colour Doppler examination, the authors found that the left ventricular mass and its systolic-diastolic function were significantly worse in the group of 39 children with SDB than in 21 children from the control group [10]. Children from our study group were also normotensive but did not present abnormal left ventricle parameters. In this context, snoring reported by parents should not be regarded as a risk factor for myocardial overload in children.

Hypertension is one of the well-known factors that has an influence on the structure and function of the myocardium. Local remodelling and changes in the left ventricular geometry were identified to be an early symptom of hypertension. Hypertension at the time of diagnosis with left ventricular hypertrophy has already been reported in over $40 \%$ of children, and significant hypertrophy is observed in approximately $12-14 \%$ [11]. However, in the early stages of hypertension, the general function of the left ventricle is still normal, as revealed by using the parameters of EF and SF [12]. Although the subjects from the study group had higher blood pressure values at the first stage of the study, they did not meet the criteria for diagnosing hypertension. Given the lack of disturbances in the heart geometry and the systolic-diastolic function, there were no serious concerns about the left cardiac condition of the patients.

Because echocardiography is painless and widely available, attempts have been made to assess how the cardiac function indices change after tonsil removal, restoration of the upper respiratory tract patency, and an improvement of the quality of breathing. Cetin et al. conducted a study with a similar model to ours, but they obtained different results. The authors evaluated selected echocardiographic parameters of the heart in children before and after adenoidectomy, adenotonsillectomy, or tonsillectomy [13]. They examined 30 children with airway obstruction due to palatine and adenoid tonsillar hypertrophy. The presence of symptoms (snoring, sleeping with mouth open, sudden night awakenings, bedwetting, drowsiness during the day) was assessed in a similar way as in our study, based on a questionnaire completed by the parents. The patients were normotensive, as in our study. The selected cardiac function echocardiographic parameters were assessed using 2D, M-mode, and Doppler techniques. A statistically significant increase in the thickness of the interventricular septum in patients before the procedure was confirmed by $2 \mathrm{D}$ technique, compared to those after the surgery and the control group $(p=0.028)$. The other echocardiographic parameters did not change. Our study showed no significant change in the left ventricular mass index. A considerable increase in the left ventricular late diastolic dimension was observed in children six months after the surgery, which, together with a temporary increase in cardiac output and cardiac index, may result from an improvement of right ventricular parameters. However, study data do not conform this thesis. The lack of differences in left ventricular parameters between snorers and non-snorers in our study might arise from selection bias. Without polysomnography there is no evidence on the severity of the observed disturbances. Since the patient selection was not objective, only based on the parents' recollections, selection bias could cause the different results in our study and that of Cetin.

Partial confirmation of such hypothesis could be from the results of the study by Kaditis et al. [14]. They divided children into three groups according to apnoea hypopnoea index (AHI) assessed in polysomnography. Children with the most severe forms of SDB had significantly inferior results of left ventricle function than children with PS, but there were no differences in cardiac structure. Systolic blood pressure and $\mathrm{AHI}$ were significant predictors of left ventricular function, but none was a predictor of left ventricular mass index. The presence of snoring itself would probably be not enough to draw conclusions about left ventricle involvement.

It is worth mentioning that new techniques can improve our knowledge about the influence of SDB on cardiac function, despite the presence of hypertension. The study conducted by Cincin et al. may alter the attitude toward snoring reported by parents as a meaningless condition [6]. They evaluated the effect of surgery on cardiac function using conventional two-dimensional Doppler assessment of the indices extended by tissue Doppler echocardiography - a more sensitive method than the traditional examination $[14,15]$. The study included children with severe forms of tonsillar hypertrophy and symptoms of SDB, not confirmed by polysomnography but diagnosed merely on the basis of a medical history taken from the parents. The tissue Doppler echocardiography showed that the cardiac function indices of both ventricles - myocardial performance index (MPI) - significantly improved after the procedure, and this confirms the positive effect of adenotonsillectomy (AT) on the circulatory system. The study results suggest that even if changes in the left ventricle are not seen in routinely performed echocardiography, they can be present, which leads to the conclusion that tonsil hypertrophy causing SDB is not only a meaningless, benign health condition.

\section{CONCLUSIONS}

Children snoring because of tonsillar hypertrophy do not have abnormal left ventricular indices in the classic 
echocardiographic examination. However, we postulate that this condition should be quickly noticed, diagnosed, and treated individually with due attention. The medical history of snoring taken from parents is not enough to identify a group at risk for changes in the left heart function.

\section{DISCLOSURE}

The authors declare no conflict of interest.

\section{REFERENCES}

1. Kara CO, Ergin H, Kocak G, et al. Prevalence of tonsillar hypertrophy and associated oropharyngeal symptoms in primary school children in Denizli, Turkey. Int J Pediatr Otorhinolaryngol 2002; 66: 175-179.

2. Niiranen TJ, Kronholm E, Rissanen H, et al. Self-reported obstructive sleep apnea, simple snoring, and various markers of sleep-disordered breathing as predictors of cardiovascular risk. Sleep Breath 2016; 20: 589-596.

3. Baguet JP, Nadra M, Barone-Rochette G, et al. Early cardiovascular abnormalities in newly diagnosed obstructive sleep apnea. Vasc Health Risk Manag 2009; 5: 1063-1073.

4. Drager LF, Bortolotto LA, Figueiredo AC, et al. Obstructive sleep apnea, hypertension, and their interaction on arterial stiffness and heart remodeling. Chest 2007; 131: 1379-1386.

5. Martha VF, Moreira Jda S, Martha AS, et al. Reversal of pulmonary hypertension in children after adenoidectomy or adenotonsillectomy. Int J Pediatr Otorhinolaryngol 2013; 77: 237-240.

6. Cincin A, Sakalli E, Bakirci EM, Dizman R. Relationship between obstructive sleep apnea-specific symptoms and cardiac function before and after adenotonsillectomy in children with adenotonsillar hypertrophy. Int J Pediatr Otorhinolaryngol 2014; 78: 1281-1287.

7. Drukteinis JS, Roman MJ, Fabsitz RR, et al. Cardiac and systemic hemodynamic characteristics of hypertension and prehypertension in adolescents and young adults: the Strong Heart Study. Circulation 2007; 115: 221-227.

8. Chami HA, Devereux RB, Gottdiener JS, et al. Left ventricular morphology and systolic function in sleep-disordered breathing: the Sleep Heart Health Study. Circulation 2008; 117: 2599-2607.

9. Amin RS, Kimball TR, Bean JA, et al. Left ventricular hypertrophy and abnormal ventricular geometry in children and adolescents with obstructive sleep apnea. Am J Respir Crit Care Med 2002; 165: 1395-1399.

10. Villa MP, Ianniello F, Tocci G, et al. Early cardiac abnormalities and increased C-reactive protein levels in a cohort of children with sleep disordered breathing. Sleep Breath 2012; 16: 101-110.

11. Litwin $\mathrm{M}$, Niemirska A. In: Nadciśnienie tętnicze u młodzieży i młodych dorosłych, Litwin M, Januszewicz A, Prejbisz A, et al. (eds.). Medycyna Praktyczna, Kraków 2011; 241-269.

12. Palatini P, Frigo G, Vriz O, et al. Early signs of cardiac involvement in hypertension. Am Heart J 2001; 142: 1016-1023.

13. Cetin M, Bozan N. The effects of adenotonsillar hypertrophy corrective surgery on left ventricular functions and pulmonary artery pressure in children. Int J Pediatr Otorhinolaryngol 2017; 101: 41-46.

14. Kaditis A. Blood pressure after adenotonsillectomy in children with obstructive sleep-disordered breathing. Am J Respir Crit Care Med 2008; $178: 882$.

15. Jankowska A, Dudziak M. Nowe techniki echokardiograficzne w ocenie funkcji lewej komory. In: Standardy kardiologiczne 2016 okiem echokardiografisty, Płońska-Gościniak E (ed.). Medical Tribune, Warszawa 2016: 189. 